\title{
Interaction Study between Digoxin and a Preparation of Hawthorn (Crataegus oxyacantha)
}

\author{
Roberta Tankanow, MS, Helen R. Tamer, PharmD, Daniel S. Streetman, PharmD, \\ Scott G. Smith, Janice L. Welton, Thomas Annesley, PhD, Keith D. \\ Aaronson, MD, and Barry E. Bleske, PharmD, FCCP
}

Hawthorn, an herbal supplement, is currently being evaluated for the treatment of heart failure. The flavonoid components of hawthorn may be responsible for hawthorn's beneficial effects in the treatment of heart failure. However, these components may also affect P-glycoprotein function and cause interactions with drugs that are P-glycoprotein substrates, such as digoxin, which is also used to treat heart failure. Therefore, the purpose of this study was to determine the effect of hawthorn on digoxin pharmacokinetic parameters. A randomized, crossover trial with 8 healthy volunteers was performed evaluating digoxin $0.25 \mathrm{mg}$ alone (D) for 10 days and digoxin $0.25 \mathrm{mg}$ with Crataegus special extract WS 1442 (hawthorn leaves with flowers; Dr. Willmar Schwabe Pharmaceuticals) $450 \mathrm{mg}$ twice daily $(D+H)$ for 21 days. Pharmacokinetic studies were performed for 72 hours. There were no statistically significant differences in any measured pharmacokinetic parameters. The $A U C_{0-\infty}, C_{\max }-C_{\min }, C_{\min }$, and renal clearance for the $D$ group were $79 \pm 26 \mathrm{mcg} \bullet \mathrm{h} / \mathrm{L}, 1.4$ $\pm 0.7 \mathrm{mcg} / \mathrm{L}, 0.84 \pm 0.2 \mathrm{mcg} / \mathrm{L}$, and $74 \pm 10 \mathrm{~mL} / \mathrm{min}$ versus 73 $\pm 20 \mathrm{mcg} \bullet \mathrm{h} / \mathrm{L}, 1.1 \pm 0.1 \mathrm{mcg} / \mathrm{L}, 0.65 \pm 0.2 \mathrm{mcg} / \mathrm{L}$, and $81 \pm 22$ $\mathrm{mL} / \mathrm{min}$ for the $D+$ H group, respectively $(\mathrm{p}>0.05)$. Following 3 weeks of concomitant therapy, hawthorn did not significantly alter the pharmacokinetic parameters for digoxin. This suggests that both hawthorn and digoxin, in the doses and dosage form studied, may be coadministered safely.

Keywords: Hawthorn; digoxin; pharmacokinetics; heart failure

Journal of Clinical Pharmacology, 2003;43:637-642 C2003 the American College of Clinical Pharmacology
C rataegus oxyacantha, an extract of the herbal supplement hawthorn, has been used to treat a number of cardiovascular ailments, including heart failure, angina pectoris, and hypertension. Studies have shown that Crataegus extract may have positive inotropic, vasodilatory, and antioxidative properties. ${ }^{1-3}$ This compound also improves endothelial function. ${ }^{4,5}$ Based in part on these effects, Crataegus extract (haw-

From the University of Michigan College of Pharmacy and University of Michigan Health Systems, Ann Arbor, Michigan (Ms. Tankanow, Dr. Tamer, Dr. Streetman, Mr. Smith, Ms. Welton, Dr. Bleske) and the Department of Pathology (Dr. Annesley) and Department of Internal Medicine (Dr. Aaronson), University of Michigan Health Systems, Ann Arbor, Michigan. Supported in part by University of Michigan Health Systems Clinical Research Resource Committee and by General Clinical Research Center Grant No. M01-RR00042. Submitted for publication September 26, 2002; revised version accepted February 22, 2003. Address for reprints: Barry E. Bleske, PharmD, University of Michigan, College of Pharmacy, 428 Church Street, Ann Arbor, MI 48109-1065.

DOI: $10.1177 / 0091270003253417$ thorn) is currently being studied for the treatment of heart failure in a large mortality trial. ${ }^{6}$

Hawthorn is made up of a number of compounds, including flavonoids, which may be responsible for hawthorn's cardiovascular effects. ${ }^{6}$ In addition, recent studies evaluating other natural compounds that contain flavonoids as well as flavonoids themselves have demonstrated alterations in P-glycoprotein activity. ${ }^{7-11}$ This may have important consequences in regard to drugs that are P-glycoprotein substrates. Since Pglycoprotein is found in high amounts in both the gut and kidney and is an efflux transporter, change in activity can lead to alterations in the absorption and clearance of drugs that are P-glycoprotein substrates.

One drug that is a P-glycoprotein substrate is digoxin. Digoxin is indicated for the treatment of symptomatic heart failure due to systolic dysfunction. ${ }^{12}$ If hawthorn is shown to be beneficial in the treatment of heart failure, it is likely that it will be coadministered with digoxin. A hawthorn-digoxin interaction is 
widely noted in the herbal medicine literature, but neither case reports nor pharmacokinetic/ pharmacodynamic data have been reported. Since hawthorn may theoretically alter P-glycoprotein activity due to its flavonoid components, it therefore may also affect digoxin pharmacokinetic parameters. The purpose of this study was to determine if hawthorn, when coadministered with digoxin, would alter digoxin pharmacokinetic parameters. The findings from this study may have important implications regarding treatment of heart failure with hawthorn.

\section{METHODS}

A total of 8 healthy subjects completed an open-label, randomized crossover trial evaluating the effect of hawthorn on the pharmacokinetic parameters of digoxin. After approval from the human subject institutional review board and before study entry, informed consent was obtained from each subject. Inclusion criteria included the following: age $>18$ years, serum creatinine $<1.2 \mathrm{mg} / \mathrm{dL}$, and bilirubin $<1.5 \mathrm{mg} / \mathrm{dL}$. Individuals taking concurrent scheduled medications (excluding oral contraceptives), those with significant medical histories, and smokers and pregnant females were excluded from the study. Subjects were also prohibited from taking vitamins, dietary supplementation, or herbal supplements during the study period. Grapefruit juice, grape juice, and red and white wine were also prohibited throughout the study period.

Subjects were admitted as outpatients to the General Clinical Research Center, and after physical examination and baseline laboratory measurements were obtained, patients were randomized into one of two groups: digoxin $0.25 \mathrm{mg}$ daily for a 10-day period (D) or digoxin $0.25 \mathrm{mg}$ daily and Crataegus special extract WS 1442 twice daily (one tablet contained 450 mg dry extract of hawthorn leaves with flowers standardized to $84.3 \mathrm{mg}$ of oligomeric procyanidines; Dr. Willmar Schwabe Pharmaceuticals, Karlsruhe, Germany) for a 21-day period $(\mathrm{D}+\mathrm{H})$. A 21-day period was employed for the $\mathrm{D}+\mathrm{H}$ treatment group to allow for steady-state concentrations for both digoxin and hawthorn. Only a 10-day period was used for the $\mathrm{D}$ group since steadystate levels would be achieved by this time and would therefore decrease the exposure of healthy volunteers to digoxin. After each treatment period, there was a 21day washout period, and subjects were then crossed over to the opposite treatment. Compliance was determined by measuring digoxin trough levels after 5 days (also used as a safety measurement) and comparison with trough digoxin levels on pharmacokinetic sampling days and by medication vial inspection. Digoxin was administered at $0900 \mathrm{~h}$ and hawthorn at $0900 \mathrm{~h}$ and $2100 \mathrm{~h}$.

Pharmacokinetic data were collected during 12hour clinic stays starting on digoxin-only day 10 and on digoxin + hawthorn day 21 . Blood samples $(7 \mathrm{~mL}$, no anticoagulant) were drawn from each subject immediately before administration of digoxin and/or hawthorn (time 0) and then at 0.25, 0.5, 1, 1.5, 2, 4, 6, 8, and 12 hours after administration of the medications; subjects were fitted with hep-lock catheters to facilitate the repeated blood draws. Catheters were removed after the 12-hour blood draw. Subjects were required to return to the clinic for blood draws at 24,48 , and 72 hours after the initial blood draw. Urine was also collected for a 24-hour time period, beginning at the baseline blood draw for determination of digoxin renal clearance. All patients were asked to void prior to the start of the collection period. For the $\mathrm{D}+\mathrm{H}$ group, hawthorn administration continued throughout the 72-hour data collection period. Pharmacodynamic measurements included blood pressure (three measurements, $5 \mathrm{~min}$ apart, in seated position by automated blood pressure machine; Alaris Medical Systems IVAC Vitacheck Model 4415) and a standard 12-lead electrocardiogram (for heart rate and PR interval measurements), which was obtained prior to and after each treatment phase. All patients were required to be in a seated position for at least 15 minutes prior to pharmacodynamic assessment. Subjects were questioned about side effects or adverse reactions between days 5 and 7 in the $\mathrm{D}$ phase and between days 8 and 10 in the $\mathrm{D}+\mathrm{H}$ phase.

\section{Digoxin Analysis}

Serum and urine samples were assayed for digoxin using the kinetic interaction of microparticles in solution (KIMS) immunoassay technique on a Roche Integra analyzer. The assay has a validated test range of 0.2 to 0.5 $\mathrm{ng} / \mathrm{mL}$. Any samples with an initial concentration above $5.0 \mathrm{ng} / \mathrm{mL}$ were diluted with a zero calibrator and reanalyzed. The interassay coefficients of variation were $9.6 \%$ at $0.85 \mathrm{ng} / \mathrm{mL}$ and $3.6 \%$ at $3.45 \mathrm{ng} / \mathrm{mL}$. To determine if hawthorn interfered with the digoxin assay, 2 subjects were administered $450 \mathrm{mg}$ of hawthorn twice a day for 7 days. After 7 days, blood samples were obtained and measured for digoxin concentrations. Both samples demonstrated serum digoxin concentrations below the detectable range of the assay $(<0.2 \mathrm{ng} /$ $\mathrm{mL}$ ). 


\section{Data Analysis}

Pharmacokinetic parameters were determined by noncompartmental methods and inspection of the data, when appropriate. Specifically, the area under the serum concentration-time curve (AUC) to 24 hours $\left(\mathrm{AUC}_{0-24}\right)$ and to the last measured time point $\left(\mathrm{AUC}_{0-72}\right)$ was determined by the linear trapezoidal method with extrapolation to infinity $\left(\mathrm{AUC}_{0-\infty}\right)$. The elimination halflife $\left(t_{1 / 2}\right)$ was determined by linear regression analysis of the terminal phase of the log concentration-time profile. The minimal serum concentrations $\left(\mathrm{C}_{\min }\right)$, maximal serum concentration $\left(\mathrm{C}_{\max }\right)$, and time to $\mathrm{C}_{\max }\left(\mathrm{t}_{\max }\right)$ were determined by inspection of the available data points. Renal clearance $\left(\mathrm{CL}_{\mathrm{R}}\right)$ was calculated as the total amount of unchanged drug excreted into the urine (Ae) over 24 hours divided by the $\mathrm{AUC}_{0-24}$. Statistical comparison between the two phases was performed by a paired $t$-test. A $p \leq 0.05$ was considered the critical probability level. The reported data are represented as the mean and standard deviation.

\section{RESULTS}

There were 11 subjects screened with a total of 8 patients completing the study, 4 male and 4 female. The subjects ranged in age from 19 to 43 years old (mean = $28 \pm 6$ ) with a mean weight of $69 \pm 13 \mathrm{~kg}$. One subject did not complete the study due to palpitations that were thought to be secondary to digoxin, and 1 patient was not able to complete the study due to a family emergency. One volunteer withdrew from the study for personal reasons before beginning the protocol. In regard to compliance, inspection of subject medication vials indicated that no doses were missed. In addition, there was no difference in digoxin trough concentrations at the mid-phase safety check and at the start of pharmacokinetic sampling $(0.69 \pm 0.4 \mathrm{mcg} / \mathrm{L}$ vs. 0.84 $\pm 0.2 \mathrm{mcg} / \mathrm{L}$ for the $\mathrm{D}$ group and $0.63 \pm 0.1$ vs. $0.65 \pm 0.2$ $\mathrm{mcg} / \mathrm{L}$ for the $\mathrm{D}+\mathrm{H}$ group, $p>0.05$, respectively).

Mean pharmacokinetic parameters for serum concentrations of digoxin are shown in Table I, and the mean serum concentration-time profiles are displayed in Figure 1. Overall, digoxin concentrations are slightly lower in the $\mathrm{D}+\mathrm{H}$ group. However, there were no statistical differences between the two groups. For $\mathrm{C}_{\min }$, the difference approached significance $(p=0.054)$, with 6 of 8 patients in the $\mathrm{D}+\mathrm{H}$ group having lower concentrations as compared to the D group.

Overall, there were no significant differences in the pharmacodynamic parameters measured from baseline values for either group. The baseline PR interval for the
Table I Pharmacokinetic Parameters

\begin{tabular}{lccc}
\hline \hline Parameter & D & D + H & \% Change \\
\hline $\mathrm{AUC}_{0-24}(\mathrm{ng} \bullet \mathrm{h} / \mathrm{mL})$ & $23 \pm 4$ & $22 \pm 4$ & -6 \\
$\mathrm{AUC}_{0-72}(\mathrm{ng} \bullet \mathrm{h} / \mathrm{mL})$ & $49 \pm 9$ & $46 \pm 11$ & -7 \\
$\mathrm{AUC}_{0-\infty}(\mathrm{ng} \bullet \mathrm{h} / \mathrm{mL})$ & $79 \pm 26$ & $73 \pm 20$ & -8 \\
$\mathrm{C}_{\max }(\mathrm{ng} / \mathrm{mL})$ & $2.1 \pm 0.6$ & $1.8 \pm 0.2$ & -14 \\
$\mathrm{C}_{\min }(\mathrm{ng} / \mathrm{mL})$ & $0.84 \pm 0.2$ & $0.65 \pm 0.2$ & -23 \\
$\mathrm{C}_{\max }-\mathrm{C}_{\min }(\mathrm{ng} / \mathrm{mL})$ & $1.4 \pm 0.7$ & $1.1 \pm 0.1$ & -17 \\
$\mathrm{t}_{\max }(\mathrm{h})$ & $1.3 \pm 0.5$ & $1.0 \pm 0.5$ & -23 \\
$\mathrm{t}_{1 / 2}(\mathrm{~h})$ & $50 \pm 15$ & $48 \pm 6$ & -4 \\
$\mathrm{CL}_{\mathrm{R}}(\mathrm{mL} / \mathrm{min})$ & $74 \pm 10$ & $81 \pm 22$ & +9 \\
\hline
\end{tabular}

Results expressed as mean \pm standard deviation. $\mathrm{D}$, digoxin-alone group; $\mathrm{D}+$ $\mathrm{H}$, digoxin and hawthorn group; AUC, area under the concentration-time curve; $\mathrm{C}_{\max }$, maximum concentration; $\mathrm{C}_{\min }$, minimum concentration; $t_{\max }$, time to maximum concentration; $t_{1 / 2}$, half-life; $\mathrm{CL}_{\mathrm{R}}$, renal clearance.

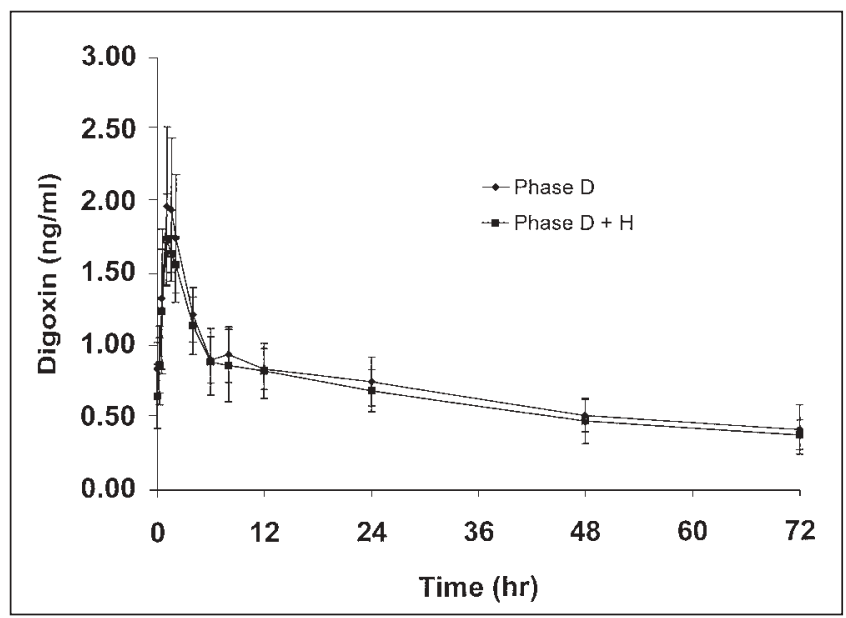

Figure 1. Mean serum concentration-time curve for digoxin. D, digoxin alone; $D+H$, digoxin + hawthorn.

$\mathrm{D}$ and $\mathrm{D}+\mathrm{H}$ phases was $149 \pm 20 \mathrm{msec}$ and $150 \pm 16$ msec ( $p>0.05)$, respectively. Following each phase, the PR interval increased to $156 \pm 24 \mathrm{msec}$ and $152 \pm 14$ msec for $\mathrm{D}$ and $\mathrm{D}+\mathrm{H}$, respectively. The mean change in $\mathrm{PR}$ interval for $\mathrm{D}$ and $\mathrm{D}+\mathrm{H}$ was $6.5 \pm 11 \mathrm{msec}$ versus $1.0 \pm 13 \mathrm{msec}(p>0.05)$, respectively. Baseline heart rate (HR) during the $\mathrm{D}$ and $\mathrm{D}+\mathrm{H}$ phases was $65 \pm 6$ beats/min and $64 \pm 6$ beats/min ( $p>0.05)$, respectively. Following each phase, the HR was $62 \pm 4$ and $65 \pm 7$ for $\mathrm{D}$ and $\mathrm{D}+\mathrm{H}$, respectively. The mean change in HR for $\mathrm{D}$ and $\mathrm{D}+\mathrm{H}$ was $-2.5 \pm 8$ beats/min and $1 \pm 6$ beats $/ \mathrm{min}$ $(p>0.05)$, respectively.

The hawthorn and digoxin were well tolerated. In the digoxin-only group, 1 patient noted nausea, which 
lasted for 1 to 2 days, and in the $\mathrm{D}+\mathrm{H}$ group, 2 patients complained of mild nausea, which resolved in 1 day. In the combination group, 1 subject complained of flatulence and insomnia, and 1 subject complained of headache and dizziness. These effects were mild and resolved in a day.

\section{DISCUSSION}

This study demonstrated no statistically significant difference in digoxin pharmacokinetic or pharmacodynamic parameters when coadministered with hawthorn over a 3-week time period. These findings are in contrast with those that have demonstrated significant reductions in digoxin $\mathrm{AUC}, \mathrm{C}_{\max }$, and $\mathrm{C}_{\min }$ when digoxin was given together with St. John's wort, a compound containing many of the same constituents as hawthorn. ${ }^{7}$ These differences were at least partly attributed to induction of the P-glycoprotein transporter. ${ }^{7}$ In particular, both are rich in various flavonols, including rutin, quercetin, isoquercitrin, and hyperoside, all of which are present in both products. ${ }^{13-15}$ These similarities are of significance as prior publications have suggested that compounds such as rutin, quercetin, and hyperoside may be capable of altering the activity of various drug-metabolizing enzymes. ${ }^{16}$ Even more significant in relation to effects on digoxin is the mounting evidence that quercetin, present in both St. John's wort and hawthorn, is capable of altering Pglycoprotein-mediated drug transport. ${ }^{10,11,17}$ It could also be hypothesized that rutin and isoquercitrin, both quercetin glycosides, have similar abilities to alter Pglycoprotein activity. Erlund et $\mathrm{al}^{18}$ demonstrated that quercetin was present in plasma following oral administration of both quercetin aglycone and rutin and that both quercetin and rutin are mainly present in the plasma as quercetin glucuronides and/or sulfates.

Despite the similarities between hawthorn and St. John's wort, important differences in their constituents may contribute to their disparate effects on digoxin pharmacokinetics. In addition to its flavonol content, hawthorn contains numerous other compounds, including chlorogenic acid, epicatechin, ursolic acid, and proticatecholic acid, none of which have been shown to alter drug metabolism or transport. Conversely, some additional compounds in St. John's wort include hyperforin, adhyperforin, and hypericin. Perloff et $\mathrm{al}^{19}$ have shown that hypericin strongly induces P-glycoprotein in vitro and may be the principle component responsible for the P-glycoprotein induction observed with St. John's wort in vivo. Thus, it is likely that these differences explain why hawthorn did not alter digoxin pharmacokinetics to a similar extent as previous studies of St. John's wort.

These findings have important implications not only for the concomitant use of digoxin and hawthorn but also for the likely impact of hawthorn on other Pglycoprotein substrates. Digoxin is well recognized as a P-glycoprotein substrate ${ }^{20}$ and is only minimally metabolized in humans. ${ }^{21}$ As a result, digoxin has been widely used as a model P-glycoprotein substrate. The relatively weak effects of hawthorn on digoxin observed herein suggest that, at similar doses, hawthorn is unlikely to alter the P-glycoprotein-mediated transport of other compounds.

The lack of a pharmacokinetic interaction between hawthorn and digoxin does not, however, rule out a pharmacodynamic interaction, which is particularly concerning given their potential for use in similar patient populations. As a result, we evaluated ECG, heart rate, and blood pressure parameters and found no evidence of any such interaction. However, there is still a distinct possibility that hawthorn may increase digoxin's effect on contractility. As more is learned about the mechanism(s) by which hawthorn works in heart failure, it is becoming increasingly clear that it is unique from that of digoxin. Although, like digoxin, there is some evidence of positive inotropic effects associated with hawthorn, hawthorn is associated with a slight increase in heart rate, opposite of what would be expected with digoxin. ${ }^{2}$ Furthermore, one of the main effects of hawthorn seems to be its ability to produce endothelium-dependent vasodilation, an effect not seen with digoxin..$^{2,5,22}$

In the interpretation of both the pharmacokinetic and the pharmacodynamic results, particular aspects of the study design and study limitations warrant additional consideration. First, as part of the study design, hawthorn was administered simultaneously with digoxin. Coadministration in this manner allowed for inference regarding both P-glycoprotein activity and other factors, such as physiochemical effects, that may alter digoxin absorption. Our results indicate no significant differences in absorption as determined by $\mathrm{C}_{\max }$ $\mathrm{C}_{\min }$ and $\mathrm{t}_{\max }$ values, suggesting that simultaneous administration is unlikely to affect digoxin absorption. Furthermore, since we did not administer intravenous digoxin, the actual effect on digoxin bioavailability is unknown. Along this line, our results may also be explained if hawthorn blocked P-glycoprotein in the gut and at the same time reduced the amount of digoxin available for absorption through a physical or chemical interaction. It should also be emphasized that this only applies to digoxin, as it is not known whether haw- 
thorn absorption is affected. While we did not measure hawthorn's individual components, we did use a standardized product made by a reputable manufacturer, making lack of hawthorn absorption highly unlikely.

Second, although no statistically significant pharmacokinetic interaction was observed, close inspection of the data suggests that hawthorn coadministration does result in a quantitatively small decrease in absorption and increase in the clearance of digoxin, presumably related to the mild induction of Pglycoprotein activity. This interpretation is based on the finding that AUC, $\mathrm{C}_{\max }, \mathrm{C}_{\max }-\mathrm{C}_{\min }$, and $\mathrm{C}_{\min }$ were lower and renal clearance was higher in the digoxin plus hawthorn group. In fact, $\mathrm{C}_{\min }$ was approximately $22 \%$ lower in this group, a difference that approached our a priori threshold level $(p \leq 0.05)$ for statistical significance $(p=0.054)$. The reason that these more modest differences were not considered statistically significant is that the study was only adequately powered to detect differences of $\geq 25 \%$. Even though our findings suggest that hawthorn causes mild induction $(<25 \%$ change) of P-glycoprotein activity, the clinical significance of this is anticipated to be minor in most patients. Certainly, the concern expressed in the clinical herbal medicine literature that hawthorn could increase the risk of digoxin toxicity is not supported by this study.

A third consideration is that the true half-life for many of the hawthorn constituents is unknown. In the absence of definitive pharmacokinetic studies of hawthorn, we assumed that 21 days would be sufficient time to reach hawthorn steady state. Whether a longer study period would yield significant results is unknown. It should be mentioned that the study time period for the St. John's wort study was 15 days and that other studies have shown alterations in P-glycoprotein activity (inhibition or induction) over a much shorter time period than 21 days. ${ }^{11,17}$

Finally, this study was done in normal subjects and used only one dosage of hawthorn. Whether differences would be seen in patients with heart failure, the likely setting for coadministration, or with higher hawthorn doses is unknown. However, the dosage investigated herein is identical to that being used in a largescale clinical trial of hawthorn ${ }^{6}$ and is similar to or higher than doses from numerous studies cited in a recent review of hawthorn pharmacology. ${ }^{23}$

In conclusion, coadministration of hawthorn with digoxin resulted in only modest changes in digoxin pharmacokinetics, differences that did not achieve statistical significance. We hypothesize that these differences are a result of mild P-glycoprotein induction likely due to the presence of quercetin and various quercetin glycosides in the hawthorn extract. In addition, there was no evidence of any pharmacodynamic interaction, as measured by ECG, heart rate, and blood pressure. In total, these findings suggest that both drugs may be given together safely in the clinical setting in the doses studied.

The authors would like to acknowledge the support of the General Clinical Research Staff. Their assistance was invaluable and appreciated.

\section{REFERENCES}

1. Munch G, Brixius K, Frank K, Erdmann E: WS 1442 (extract of Crataegus species) increases force of contraction in human failing myocardium by inhibition of the $\mathrm{Na}^{+} / \mathrm{K}^{+}$-ATPase. Circulation 1997; 96(Suppl.):4090.

2. Schussler M, Holzl J, Fricke W: Myocardial effects of flavonoids from Crataegus species. Arzneimittelforschung 1995;45:842-845.

3. Bahorun T, Gressier B, Trotin F, Brunet C, Dine T, Luyckx M, et al: Oxygen species scavenging activity of phenolic extracts from hawthorn fresh plant organs and pharmaceutical preparations. Arzneimittelforschung 1996;46:1086-1089.

4. Chen ZY, Zhang ZS, Kwan KY, Zhu M, Ho WKK, Huang Y: Endothelium-dependent relaxation induced by hawthorn extract in rat mesenteric artery. Life Sci 1998;63:1983-1991.

5. Kim SH, Kang KW, Kim KW, Kim ND: Procyanidins in Crataegus extract evoke endothelium-dependent vasorelaxation in rat aorta. Life Sci 2000;67:121-131.

6. Holubarsch CJF, Colucci WS, Meinertz T, Gaus W, Tendera M: Survival and prognosis: investigations of Crataegus extract WS 1442 in congestive heart failure (SPICE): rationale, study design, and study protocol. Eur J Heart Failure 2000;2:431-437.

7. Johne A, Brockmoller J, Bauer S, Agathe M, Langheinrich M, Roots I: Pharmacokinetic interaction of digoxin with an herbal extract from St. John's wort (Hypericum perforatum). Clin Pharmacol Ther 1999;66:338-345.

8. Critchfield JW, Welsh CJ, Phang JM, Yeh GC: Modulation of adriamycin accumulation and efflux by flavonoids in HCT-15 colon cells. Biochem Pharmacol 1994;48:1437-1445.

9. Conseil G, Cortay HB, Dayan G, Jault JM, Barron D, Di Pietro A: Flavonoids: a class of modulators with bifunctional interactions at vicinal ATP- and steroid-binding sites on mouse P-glycoprotein. ProC Natl Acad Sci USA 1998;95:9831-9836.

10. Shapiro AB, Ling V: Effect of quercetin on hoechst 33342 transport by purified and reconstituted P-glycoprotein. Biochem Pharmacol 1997;53:587-596.

11. Phang JM, Poore CM, Lopaczynska J, Yeh GC: Flavonol-stimulated efflux of 7,12-dimethylbenz(a)anthracene in multidrug-resistant breast cancer cells. Cancer Res 1993;53:5977-5981.

12. Heart Failure Society of America: Guidelines for management of patients with heart failure caused by left ventricular systolic dysfunction-pharmacological approaches. J Cardiac Failure 1999; 5:357-382.

13. Nahrstedt A, Butterweck V: Biologically active and other chemical constituents of the herb of Hypericum perforatum L. Pharmacopsychiatry 1997;30(Suppl.):129-134. 
14. Chang Q, Zhu M, Zuo Z, Chow M, Ho WK: High-performance liquid chromatographic method for simultaneous determination of hawthorn active components in rat plasma. J Chromatogr B Biomed Sci Appl 2001;760:227-235.

15. Zhang Z, Chang Q, Zhu M, Huang Y, Ho WK, Chen Z: Characterization of antioxidants present in hawthorn fruits. J Nutr Biochem 2001;12:144-152.

16. Obermeier MT, White RE, Yang CS: Effects of bioflavonoids on hepatic P450 activities. Xenobiotica 1995;25:575-584.

17. Scambia G, Ranelletti FO, Panici PB, De Vincenzo R, Bonanno G, Ferrandina G, et al: Quercetin potentiates the effect of adriamycin in a multidrug-resistant MCF-7 human breast-cancer cell line: Pglycoprotein as a possible target. Cancer Chemother Pharmacol 1994;34:459-464.

18. Erlund I, Kosonen T, Alfthan G, Maenpaa J, Perttunen K, Kenraali $\mathrm{J}$, et al: Pharmacokinetics of quercetin aglycone and rutin in healthy volunteers. Eur J Clin Pharmacol 2000;56:545-553.
19. Perloff MD, von Moltke LL, Stormer E, Shader RI, Greenblatt DJ: Saint John's wort: an in vitro analysis of P-glycoprotein induction due to extended exposure. Br J Pharmacol 2001;134:1601-1608.

20. Greiner B, Eichelbaum M, Fritz P, Kreichgauer HP, von Richter O, Zundler J, et al: The role of intestinal P-glycoprotein in the interaction of digoxin and rifampin. J Clin Invest 1999;104:147-153.

21. Lacarelle B, Rahmani R, de Sousa G, Durand A, Placidi M, Cano JP: Metabolism of digoxin, digoxigenin digitoxosides and digoxigenin in human hepatocytes and liver microsomes. Fundam Clin Pharmacol 1991;5:567-582.

22. Schussler M, Holzl J, Rump AFE, Fricke U: Functional and antiischemic effects of monoacetyl-vitexinrhamnoside in different in vitro models. Gen Pharmacol 1995;26:1565-1570.

23. Rigelsky JM, Sweet BV: Hawthorn: pharmacology and therapeutic uses. Am J Health-Syst Pharm 2002;59:417-422. 